http://jmscr.igmpublication.org/home/

ISSN (e)-2347-176x ISSN (p) 2455-0450

crossref DOI: https://dx.doi.org/10.18535/jmscr/v7i7.84

Journal Of Medical Science And Clinical Research

\title{
A Comparison of Salivary and Blood Glucose in Type II Diabetics in Different Age Groups
}

Authors

\section{Sharon M.P. ${ }^{1}$, S. Srikanth ${ }^{2 *}$, A.S. Anil Kumar ${ }^{3}$}

${ }^{1}$ Assistant Professor, Department of Physiology, Believers Church Medical College, St. Thomas Nagar,

Kuttapuzha, Thiruvalla, Kerala - 689105

${ }^{2}$ Associate Professor, Department of Physiology, Kempegowda Institute of Medical Sciences, Bangalore, Karnataka - 560070

${ }^{3}$ Professor, Department of Biochemistry, Kempegowda Institute of Medical Sciences, Bangalore - 560070

*Corresponding Author

Dr S. Srikanth

Associate Professor, Department of Physiology, Kempegowda Institute of Medical Sciences, Bangalore, Karnataka - 560070, India

\begin{abstract}
Diabetes is a major cause of mortality and morbidity. However, a large percentage of diabetics live without being diagnosed. ${ }^{9}$ The early diagnosis of diabetes can prevent early, long - term complications that are responsible for the high morbidity of diabetics. This major global risk is predicted to cause substantial financial loss due to increased health care expenditure and lost productivity. ${ }^{10}$ This makes the primary prevention of diabetes and its complications, of paramount importance. It is known that diabetes affects salivary composition and function. ${ }^{8}$ This study was done to examine the effect of age on salivary and blood glucose levels in type II diabetics. Salivary and blood glucose levels were estimated and compared in both groups. The eighty adults included in our study belonged to the age group of 30 - 50 years and were divided into 2 groups - diabetics and healthy adults. Both groups were further divided into 4 groups based on age (30-35, 36-40, 41-45, 46-50 years). Blood samples were obtained from subjects after an overnight fast and 2 hours postprandial and analysed with hexokinase enzyme using an automated analyser. Saliva samples obtained from subjects after an overnight fast and 2 hours postprandial were assessed with glucose oxidase enzyme using a colorimeter. Salivary glucose levels were compared between diabetics and healthy adults by t-test. Relationship between salivary and blood glucose was assessed by correlation test. Difference in salivary and blood glucose levels between age groups was determined by Kruskal-Wallis test. Salivary glucose is significantly higher in diabetics $(P<0.001)$. Correlation flanked by salivary and blood glucose is not seen. Further studies will help in use of salivary diagnostics for early and non-invasive diagnosis of diabetes. Blood glucose is highest in 36-40 years and salivary glucose in 46-50 years age group. There is a temporal shift in the age of diagnosis of diabetes.

Keywords: Diabetes mellitus; age; blood glucose; salivary glucose.
\end{abstract}

\section{Introduction}

Diabetes mellitus (DM), a major cause of morbidity and mortality, is characterized by insulin resistance (IR), impaired insulin secretion and increased glucose production. ${ }^{11}$ According to IDF (International Diabetes Federation), in 2017, 
around 425 million adults were living with diabetes. ${ }^{9}$ The diabetes burden in Asian countries is disproportionately high in young to middleaged adults. ${ }^{13}$ The prevalence of diabetes in adults in India was estimated at $8.8 \%$ with the majority lying in the range of $40-59$ years of age. ${ }^{9}$ It has been seen that there is a greater risk of developing this disorder among Asian Indians. ${ }^{14}$ There is a rising prevalence of diabetes in India for which urbanization is to be blamed and it has even affected the rural areas. ${ }^{15}$

Saliva is an organic fluid and is made up of many constituents like glucose and amylase ${ }^{16}$ and is the first biological fluid to be affected by any change in eating habits or any environmental or physical changes. ${ }^{17}$ Glucose moves through membranes of blood vessels as it is a small molecule and then passes from the blood plasma via gingival sulcus to the gingival fluid, and reaches the saliva. ${ }^{18}$

Diabetes mellitus is known to alter salivary composition and function which disrupts the homeostasis of the oral cavity and makes it more prone for oral diseases. ${ }^{16}$ IR is a prominent feature of DM and secondary pathophysiological changes in multiple organ systems occur as a consequence of this disorder. Vascular complications develop due to changes in the metabolism of lipids and proteins. ${ }^{19}$

Previous research has shown that salivary glucose levels are raised in diabetics. ${ }^{16}$ While increased blood glucose may lead to higher levels of salivary glucose, ${ }^{12}$ a decrease in mean glucose concentration is seen in the saliva of fasting subjects when compared to the control group. ${ }^{17} \mathrm{~A}$ significant correlation was seen between postprandial serum and salivary glucose levels in both diabetics and nondiabetics $(\mathrm{P}<.001)$ in the study conducted by Gupta et al. ${ }^{21}$

Self monitoring of blood glucose has made the task of monitoring diabetes less burdensome. However, it's many disadvantages (painful, inconvenient, messy, embarrassing, expensive) cause patients to find the testing distressing. ${ }^{21}$

The limited number of studies that evaluate glucose concentration in saliva, contradictory results obtained from these studies and the fact that very few studies have been done to study the relationship between salivary and blood glucose in fasting and postprandial states in India, prompted us to carry out this study. In case, a correlation is determined between salivary and blood glucose, estimating salivary glucose levels could be used as a non-invasive method for determining glucose levels in diabetics.

According to IDF, 1 in 2 people with diabetes have gone undiagnosed worldwide in 2017. ${ }^{9}$ Undiagnosed diabetes can cause progressive microvascular and macrovascular damage and if left undiagnosed and untreated, it will result in a lower life expectancy. In 2017, diabetes caused 4 million deaths worldwide and at least 727 billion US dollars was spent on health expenditure. Therefore, it is crucial to develop innovative and improved methods of testing for diabetes to lower the disease burden.

There is a shift in age of onset of diabetes to a younger age in the recent years in India. ${ }^{22}$ This calls for a need for early identification of individuals at risk which would contribute towards prevention of or delay in the onset of diabetes. This would reduce the disease burden on the nation.

\section{Materials and Methods}

This study was done to estimate and compare salivary glucose levels in diabetics and healthy adults. The method of colorimetry was used to study this relationship and also to assess the relationship between blood glucose and salivary glucose levels.

Our study included 40 type II diabetics and 40 healthy controls $(n=80)$ in the age group of $30-$ 50 years. They were recruited from outpatients attending KIMS Hospital outpatient department, Bangalore. Type II diabetics of both genders formed part of the experimental group. Age and sex matched, non - diabetic, healthy individuals were included in the control group. These groups were again divided into 4 age - based groups, 3035 years, 36-40 years, 41-45 years and 46-50 
years. All subjects submitted written informed consent. The Ethics Review Committee of the Institution approved our study.

The exclusion criteria were severe diabetic complications, other systemic illnesses, intake of medications other than those for Diabetes mellitus, smokers, tobacco users, edentulous individuals, history of prior surgery of salivary glands, on radiotherapy of head and neck region, Sjogren's syndrome, rheumatoid arthritis or SLE and secondary diabetes.

Blood and saliva samples were assessed and glucose levels estimated in the lab in the Department of Biochemistry, Kempegowda Institute of Medical Sciences, Bangalore. BMI was calculated from data obtained (height was recorded using a stadiometer and weight to the nearest $100 \mathrm{gms}$ using a digital weighing scale) using the formula weight divided by square of height (kilograms per square meter).

In order to measure fasting and postprandial salivary glucose levels, samples of saliva were collected on an empty stomach (after 12 hours of fasting) and 2 hours postprandial. Spitting method was employed to collect saliva samples between $8 \mathrm{am}$ and $11 \mathrm{am}$. It was ensured that subjects did not have any meal or had not practised any oral hygiene 90 minutes before the time of collection. The subjects were required to gargle their mouths with about $5 \mathrm{ml}$ of distilled water for about 2 minutes and un-stimulated whole saliva samples $(5 \mathrm{ml})$ were collected in clean, dry sterile tubes. These samples were then frozen at $-20^{\circ} \mathrm{C}$ and later thawed. Following this, samples were centrifuged at 3000rpm for 20 minutes and the supernatant was stored at $-18^{\circ} \mathrm{C}$ until it was used for determining glucose levels. The analysis was done within 48-72 hours of collection and each assay was repeated three times. All data calculated were presented as mean \pm SD (Standard deviation) of the three values.

The estimation of salivary glucose was done using the Glucose Oxidase kit (Agappe Diagnostics Limited, Kerala, India) by the enzymatic colorimetric method in colorimeter (CL157) (basis of this method - oxidation of glucose by glucose oxidase (GOD) followed by determination of resulting $\mathrm{H}_{2} \mathrm{O}_{2}$ in the presence of peroxidase (POD)).

Blood samples for glucose estimation were collected on an empty stomach (after 12 hours of fasting) and 2 hours postprandial. An automated analyser (cobas e501) was used for blood glucose estimation by enzymatic colorimetric test method using the Hexokinase Kit (Agappe Diagnostics Limited, Kerala, India).

Results were expressed as mean \pm SD and the significance of any difference was tested using ttest and Mann-Whitney test wherever applicable. Differences with $\mathrm{P}$ values $<0.05$ were considered statistically significant. Spearman's rank correlation test was used to assess the correlation between blood and salivary glucose values.

\section{Results}

While the mean age of the experimental group was $42.03 \pm 5.77$ years, the mean age of the control group was $\mathbf{3 9 . 9 5} \pm \mathbf{6 . 4 3}$ years (Table 1 ) The mean BMI of the diabetic group was $25.37 \pm$ $2.57 \mathrm{~kg} / \mathrm{m}^{2}$ and that of the control group was $24.46 \pm 3.33 \mathrm{~kg} / \mathrm{m}^{2}$ (Table 1 ).

Salivary glucose is significantly higher in diabetics $(\mathrm{P}<0.001)$. Table 2 (Figures 1 \& 2) shows that the mean salivary glucose concentration in the fasting state was significantly greater than that of the study group $(\boldsymbol{P}<\mathbf{0 . 0 0 1})$ and similar results are seen for the mean salivary glucose level in the postprandial state. Correlation flanked by salivary and blood glucose is not seen in both fasting and postprandial states.

Blood glucose is highest in 36-40 years and salivary glucose in $46-50$ years age group. (Table 3, Figures 3,4,5,6)

Table 1: Characteristics of subjects

\begin{tabular}{lcc}
\hline & Diabetic group & Control group \\
\hline Males $(\mathrm{n})$ & 17 & 12 \\
Females $(\mathrm{n})$ & 23 & 28 \\
Age $($ years $)$ & $42.03 \pm 5.77$ & $39.95 \pm 6.43$ \\
BMI $\left(\mathrm{kg} / \mathrm{m}^{2}\right)$ & $25.37 \pm 2.57$ & $24.46 \pm 3.33$ \\
\hline
\end{tabular}

Values are expressed in mean \pm SD 
Table 2: Blood glucose and salivary glucose levels of the groups

\begin{tabular}{lccc}
\hline & Diabetic group & Control group & $P$ value \\
\hline Fasting blood glucose $(\mathrm{FBG})(\mathrm{mg} / \mathrm{dl})$ & $\mathbf{1 4 7 . 9 3} \pm \mathbf{6 5 . 5 0}$ & $\mathbf{8 8 . 0 0} \pm \mathbf{1 2 . 4 8}$ & $<\mathbf{0 . 0 0 1} *$ \\
Postprandial blood glucose $(\mathrm{PPBG})(\mathrm{mg} / \mathrm{dl})$ & $\mathbf{2 2 4 . 4 0} \pm \mathbf{9 0 . 2 5}$ & $\mathbf{1 2 6 . 7 3} \pm \mathbf{3 0 . 8 5}$ & $<\mathbf{0 . 0 0 1}$ \\
Fasting salivary glucose $(\mathrm{FSG})(\mathrm{mg} / \mathrm{dl})$ & $\mathbf{9 . 7 7} \pm \mathbf{5 . 3 4}$ & $\mathbf{5 . 7 7} \pm \mathbf{2 . 0 1}$ & $<\mathbf{0 . 0 0 1}$ \\
Postprandial salivary glucose $(\mathrm{PPSG})(\mathrm{mg} / \mathrm{dl})$ & $\mathbf{1 3 . 6 5} \pm \mathbf{5 . 9 2}$ & $\mathbf{1 0 . 5 7} \pm \mathbf{3 . 0 7}$ & $\mathbf{0 . 0 0 1 *}$ \\
\hline
\end{tabular}

*Statistically significant difference

Table 3: Blood glucose and salivary glucose levels of the groups

\begin{tabular}{lcccc}
\hline Age Group & $\begin{array}{c}\text { Fasting blood glucose } \\
\text { (FBG) }(\mathrm{mg} / \mathrm{dl})\end{array}$ & $\begin{array}{c}\text { Postprandial blood } \\
\text { glucose }(\mathrm{PPBG})(\mathrm{mg} / \mathrm{dl})\end{array}$ & $\begin{array}{c}\text { Fasting salivary } \\
\text { glucose }(\mathrm{FSG})(\mathrm{mg} / \mathrm{dl})\end{array}$ & $\begin{array}{c}\text { Postprandial salivary } \\
\text { glucose }(\mathrm{PPSG})(\mathrm{mg} / \mathrm{dl})\end{array}$ \\
\hline $30-35$ years & $\mathbf{1 1 3 . 9 4}$ & $\mathbf{1 6 2 . 1 2}$ & $\mathbf{6 . 8 0}$ & $\mathbf{1 0 . 2 3}$ \\
$36-40$ years & $\mathbf{1 2 9 . 1 4}$ & $\mathbf{1 9 2 . 8 2}$ & $\mathbf{7 . 2 6}$ & $\mathbf{1 2 . 6 2}$ \\
$41-45$ years & $\mathbf{1 0 9 . 3 2}$ & $\mathbf{1 5 3 . 1 6}$ & $\mathbf{7 . 2 5}$ & $\mathbf{1 1 . 4 8}$ \\
46-50 years & $\mathbf{1 1 7 . 3 6}$ & $\mathbf{1 8 8 . 0 5}$ & $\mathbf{9 . 4 8}$ & $\mathbf{1 3 . 6 0}$ \\
\hline
\end{tabular}

Values are expressed in mean

Figure 1: Mean Fasting blood glucose (FBG) and Fasting salivary glucose (FSG) in the groups

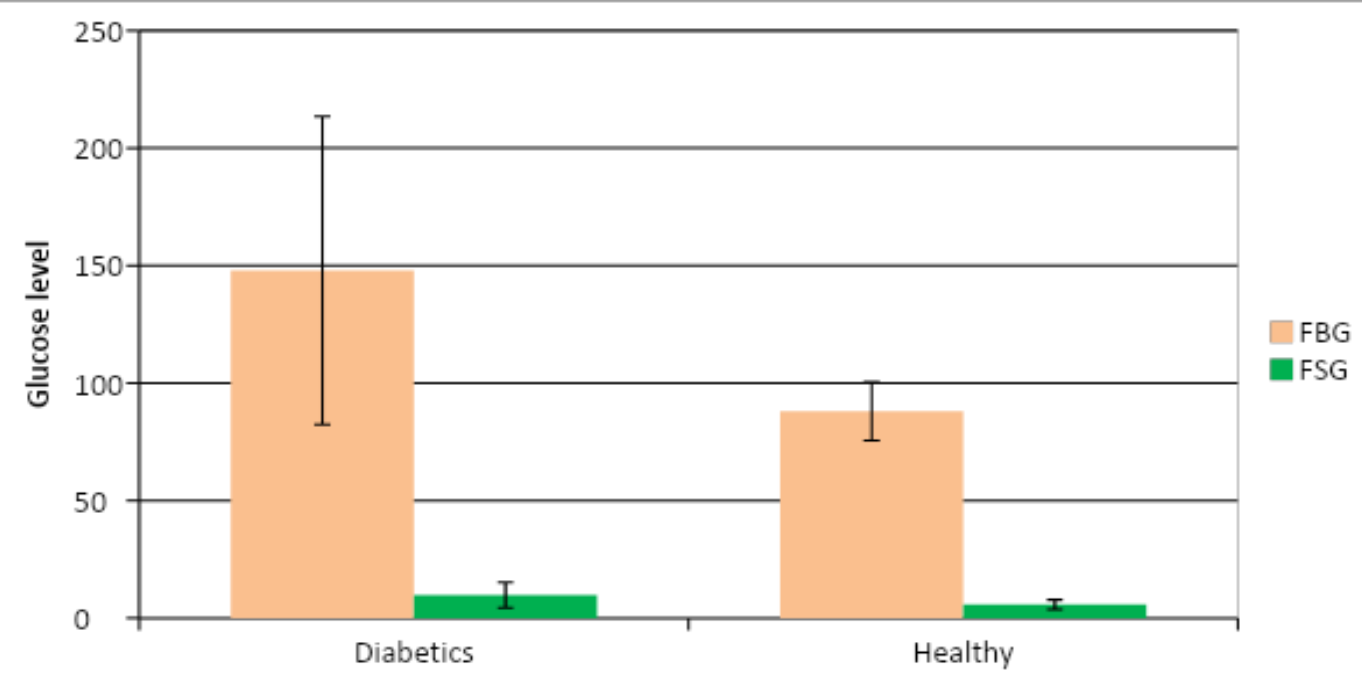

Figure 2: Mean Postprandial blood glucose (PPBG) and Postprandial salivary glucose (PPSG) in the groups

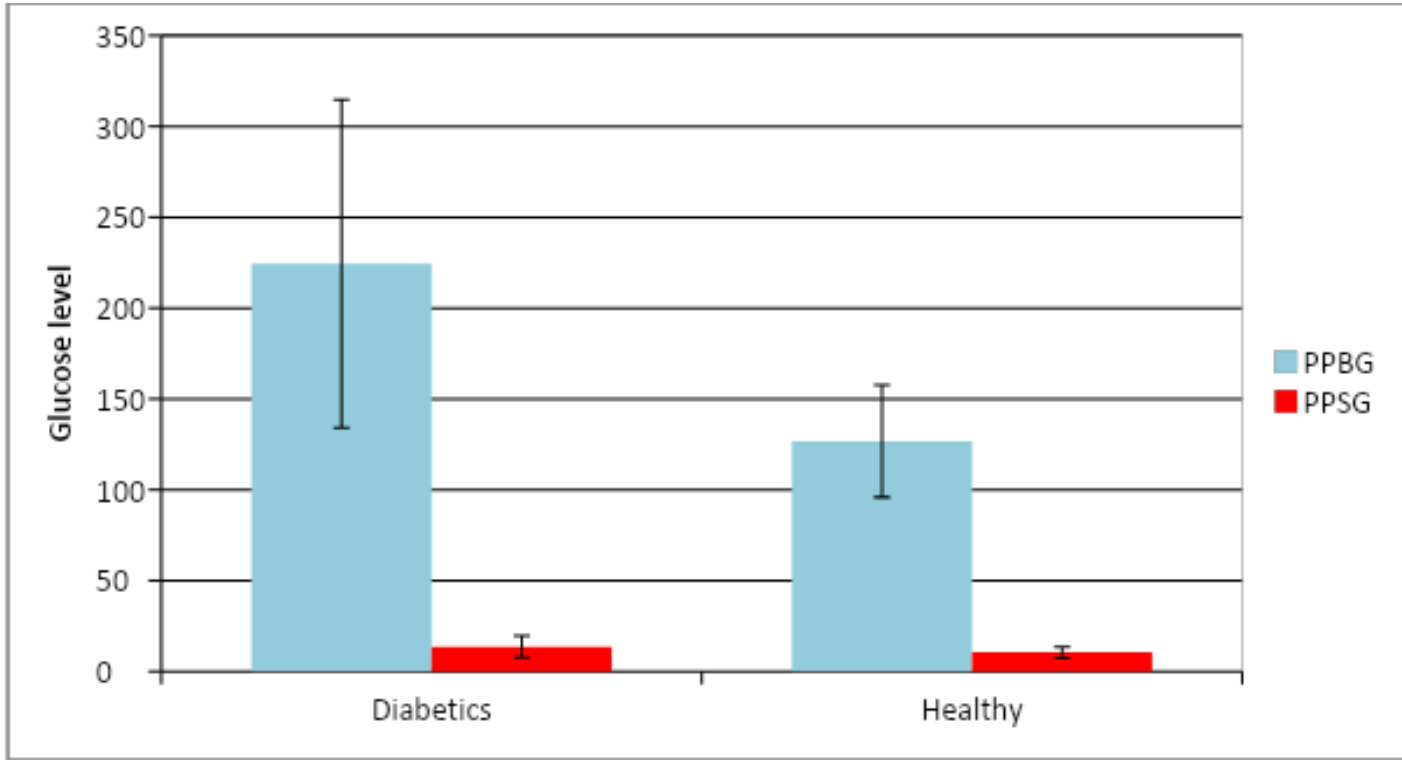


Figure 3: Mean Fasting blood glucose (FBG) in different age groups

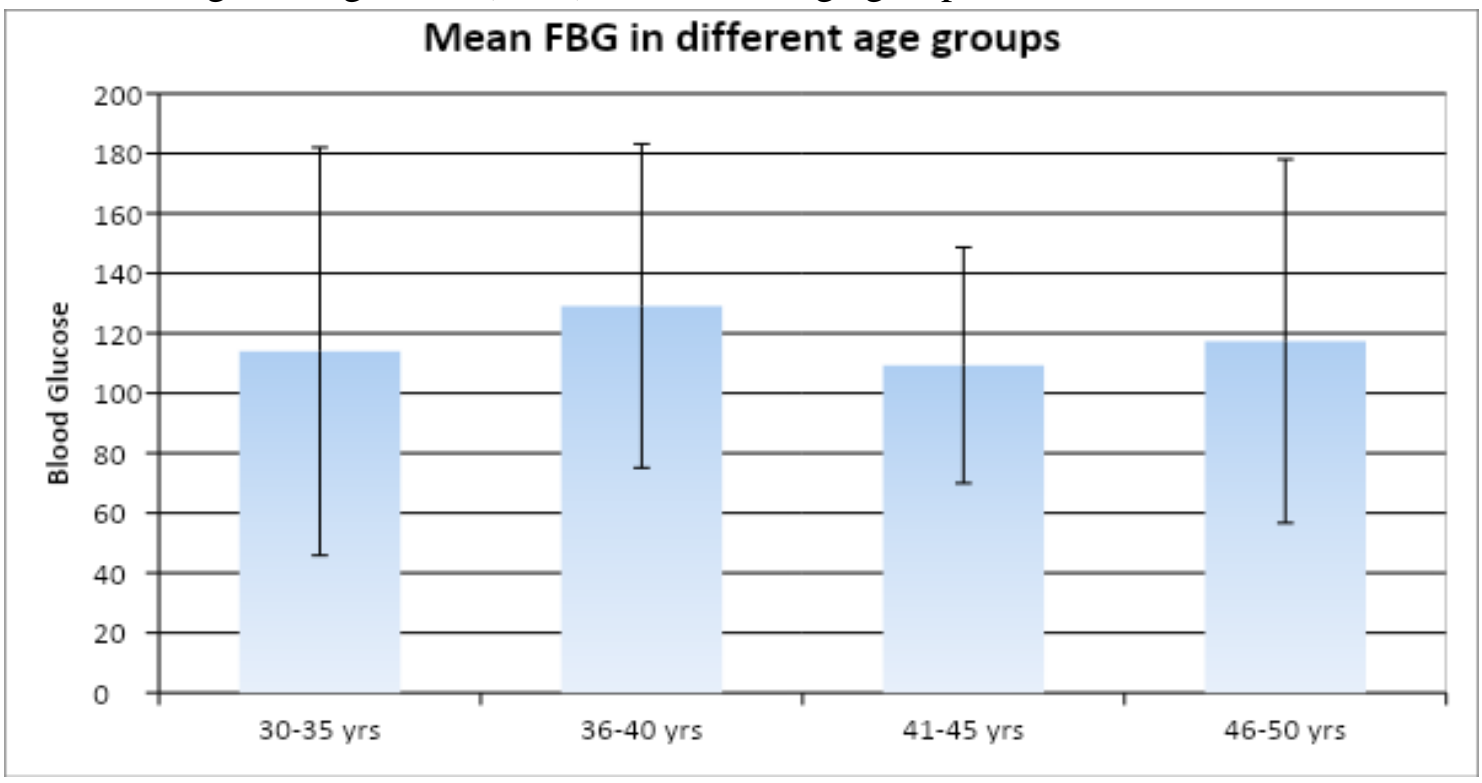

Figure 4: Mean Postprandial blood glucose (FBG) in different age groups

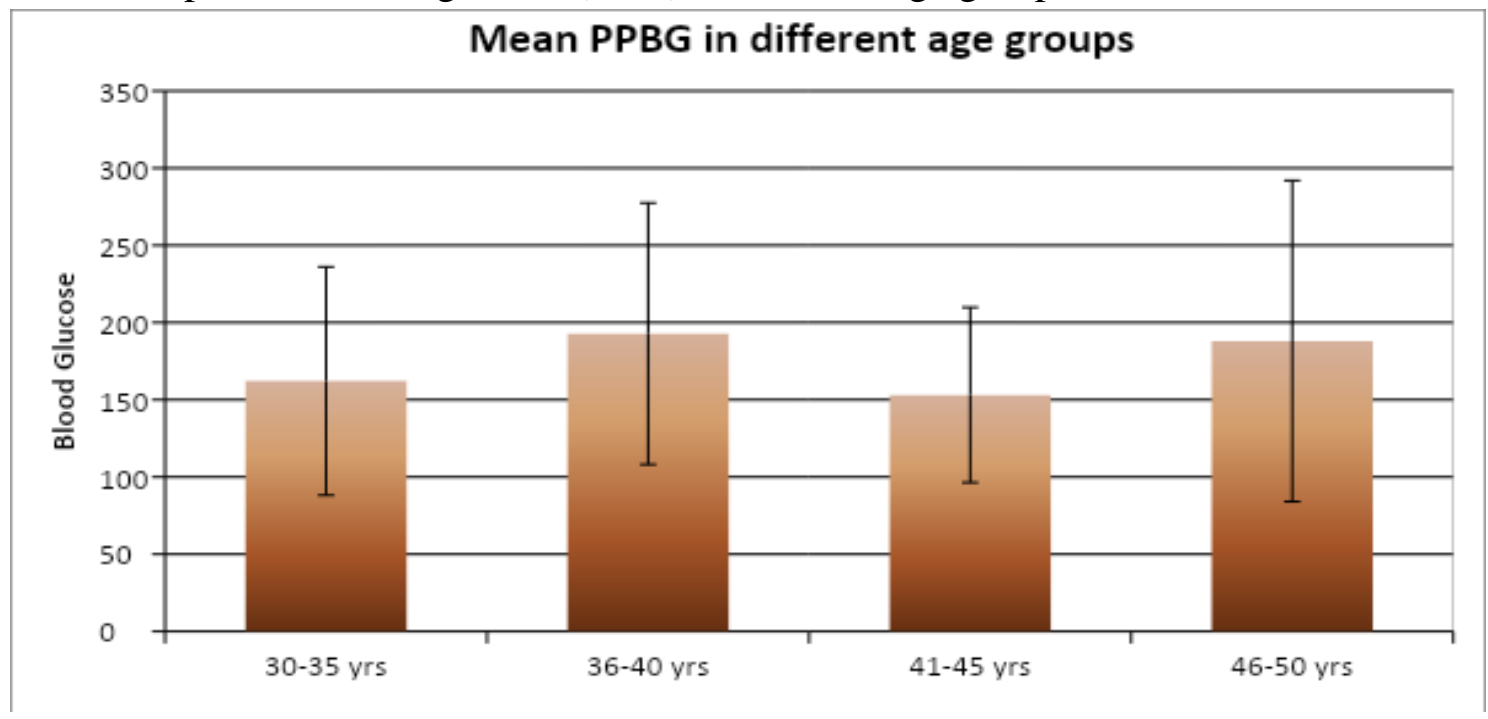

Figure 5: Mean Fasting salivary glucose (FSG) in different age groups

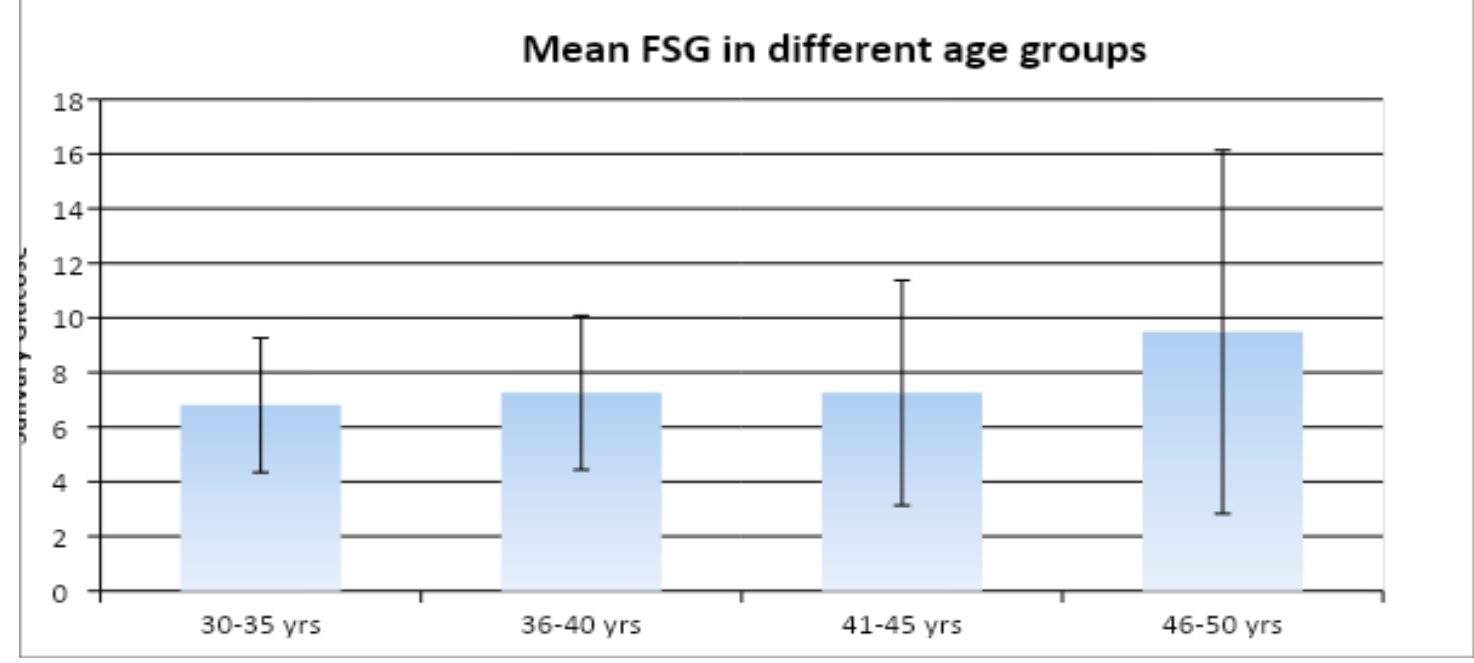


Figure 6: Mean Postprandial salivary glucose (PPSG) in different age groups

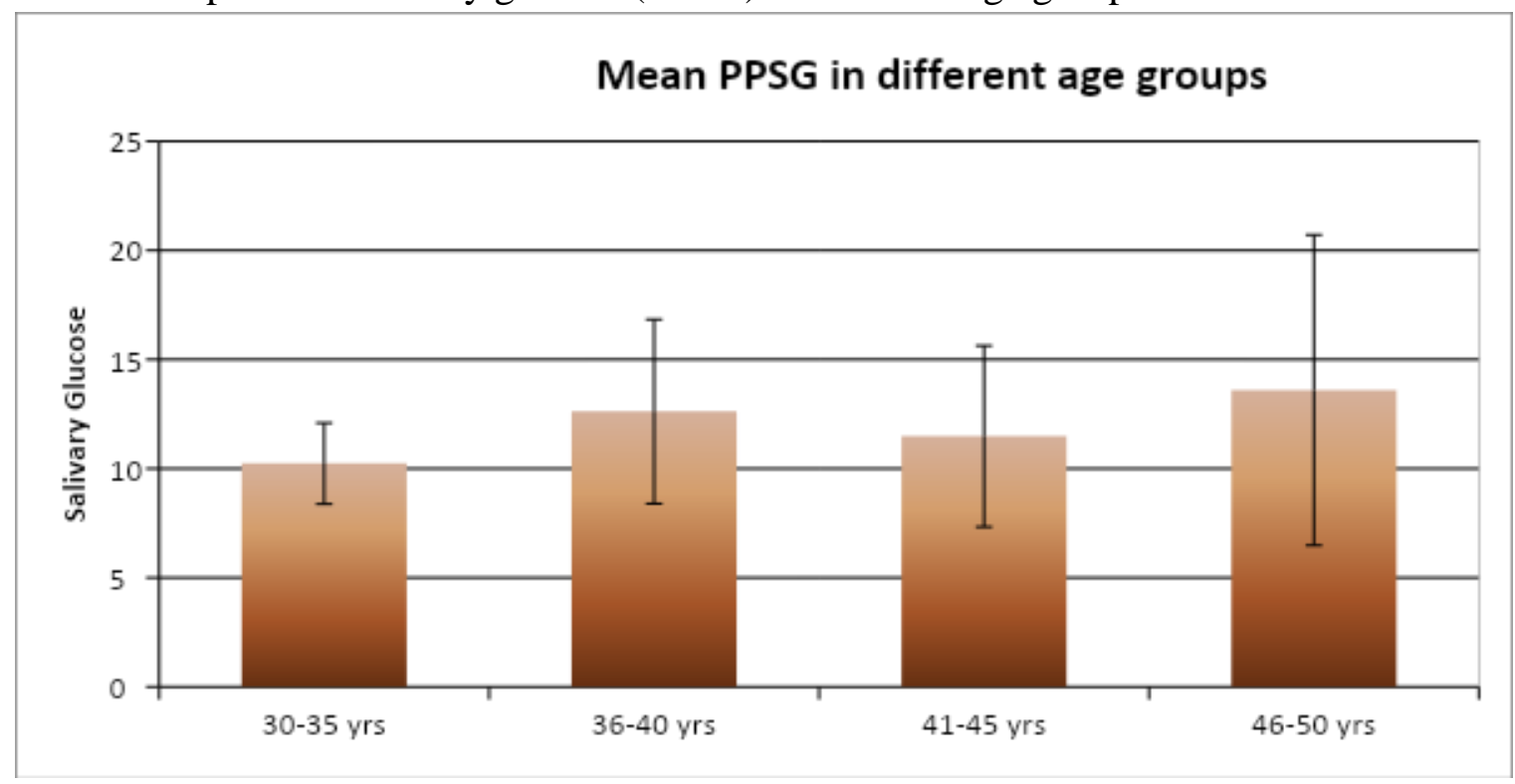

\section{Discussion}

Type II diabetes is caused by the dysregulation of insulin release from B cells and insulin resistance in peripheral tissues. It is characterised by polyuria, polydypsia and weight loss inspite of polyphagia, hyperglycemia, glucosuria, ketosis, acidosis and coma. ${ }^{25}$

Asians are possibly more genetically susceptible to insulin resistance and diabetes than Whites, ${ }^{23}$ although, the onset of diabetes is at lower BMI levels. All subjects in our study were age-, sexand BMI-matched. There was no significant difference between the mean BMI of our study group and that of our control group $(P=0.204)$ (Table 1).

In Asia, the onset of diabetes is at younger ages when compared to the Western population which could be explained by the "normal-weight metabolically obese" phenotype, increased prevalence of smoking, high alcohol intake, excessive intake of refined carbohydrates and greatly decreased physical activity levels. A role may be played in the diabetes epidemic in Asia by the fact that poor nutrition during intrauterine and early life is followed by overnutrition later in life. $^{24}$

In developing countries, diabetes is more common in the 45-64 year age range. ${ }^{15}$ This was corroborated by our study where a greater number of people affected by DM were in the age group of 46-50 years. The finding of CURES (Chennai Urban Rural Epidemiology Study) was supported by the temporal shift in the age of diagnosis of diabetes in the present study. ${ }^{16}$ Studies showing similar results have also reported a very high prevalence of undiagnosed diabetes in the community. ${ }^{17}$

Lifestyle changes (alterations in the diet or increased exercise) can often delay symptoms but most diabetics are unable to follow these strictly. ${ }^{25}$ Hyperglycaemia, a predominant consequence of $\mathrm{DM}$, in due course, causes widespread multisystem damage. Thus, though glycaemic control is important in the management of type II DM, care must be taken to detect or manage DM related complications early. ${ }^{11}$ It is possible to identify at-risk individuals early using simple screening methods like the Indian Diabetes Risk Score (IDRS). This would greatly contribute towards preventing or postponing the onset of diabetes and thus reducing the burden on the nation. $^{18,19}$

Sulphonylureas and biguanides the oral hypoglycemic agents commonly used in the management of DM. ${ }^{20}$ All diabetics in our study were on these hypoglycemic agents.

Patients depend on constant monitoring to maintain normal blood glucose levels since no 
cure is known for diabetes. Investigations done conventionally include assessments of plasma glucose concentrations, glycated haemoglobin $\left(\mathrm{HbA}_{1} \mathrm{c}\right)$ and urine testing.

Amongst non invasive devices being researched to provide diabetics an alternative, saliva is currently being researched for use in diagnosis of a myriad of conditions, for e.g. Sjogren's syndrome, carcinomas and others. Saliva analysis also provides important information about the functioning of various organs in the body ${ }^{21}$ and offers superior advantages over currently developed innovative NI techniques because it can be collected by individuals with modest training. Furthermore, large populations can be screened by a cost effective approach.

In this study, FBG levels in diabetics were significantly higher than the non - diabetic group where highest value was $114 \mathrm{mg} / \mathrm{dl}(P<0.001)$. The mean FSG (Fasting salivary glucose) was found to be higher when compared to healthy adults and this was a statistically significant difference $(P<0.001)$ (Table 2) (Figure 1). Of many saliva studies done, Thorstensson et al. ${ }^{22}$ observed a similar finding for FPG levels in diabetics whereas Sashikumar et al. ${ }^{23}$ reported that FSG was greater in the experimental group.

The increase in mean PPBG (Postprandial blood glucose) in diabetics when compared to non diabetic group in our study was statistically significant $\quad(P<0.001)$. The mean PPSG (Postprandial salivary glucose) was found to be significantly higher in the study group $(P=0.001)$ (Table 2) (Figure 2). Amongst similar studies that have been conducted, Vasconcelos et al. ${ }^{10}$ found that diabetics exhibited a statistically significant higher blood glucose levels than the non diabetic group $(P=0.000)$ and also found that the concentration of salivary glucose in diabetic patients was significantly higher $(P=0.036)$.

Normal glucose levels do not affect oral health significantly but higher salivary glucose levels favour the proliferation of micro organisms. ${ }^{26}$ Murrah, Crusson and Sauk ${ }^{27}$ found changes in the basement membrane of the parotid gland of diabetic patients and diabetic membranopathy was confirmed by elevated glucose levels in saliva. Diabetic membranopathy, in turn, causes an increased percolation of glucose from blood to saliva and thus affects the salivary composition in these patients which could explain the increased levels of salivary glucose in diabetics.

The mean PPSG was significantly higher than the mean FSG in diabetics and healthy adults $(\mathrm{P}<0.001, \quad \mathrm{P}<0.001) \quad$ (Table 2). Higher postprandial salivary glucose in diabetics implies that metabolism in the study subjects increases the basal levels of salivary glucose (effects of metabolism on simple and complex carbohydrates which form the major portion of the diet of South Indians).

Correlation flanked by salivary and blood glucose was not seen. Several studies corroborated our finding. ${ }^{6,23,26}$ This finding suggests that separate mechanisms are involved in the metabolism of salivary and blood glucose but the exact mechanism is yet to be known. Also, the insulin's role in salivary glucose regulation needs to be studied. This correlation cannot be validated until the salivary glucose estimation is standardised.

The reasons we acquired findings different from studies by other researchers could be the diversity in the selection criteria of the samples and the type of design of each study, differences in the methods employed in collection of saliva and variation in age of the subjects studied, and varying levels of metabolic control in diabetic patients.

Blood glucose was highest in the age range of 36 -40 years and salivary glucose in the $46-50$ year age group. A temporal shift in the age of diagnosis was seen in this study. When young adults develop diabetes, the longer duration of exposure to hyperglycaemia leads to early development of complications. Ahmed et al found that 50 percent of the subjects in their study were diagnosed at $\leq 45$ years of age. ${ }^{35}$ This trend could be due to unhealthy lifestyle habits and stress of modern living. 36 
All subjects in our study were age and BMI matched. Ahmed et al further observed that age of diabetes diagnosis was positively associated with higher age and systolic blood pressure but not associated with $\mathrm{HbA}_{1} \mathrm{c}$, cholesterol levels or BMI (important cardiovascular risk factors). The rise in prevalence of type II DM in young adults has been seen to follow the epidemic of childhood obesity over the past two decades. Obesity in youth, family history, ethnicity and improper prenatal conditions are some the predisposing factors of diabetes in youth. ${ }^{35}$ The higher prevalence of diabetes has also led to a rise in the number of people with Metabolic Syndrome (MetS). ${ }^{38}$

Our study, thus, shows that levels of salivary glucose were higher in fasting state, as well as, postprandial state and both increases were statistically significant. No correlation was established between blood and salivary glucose levels which means that saliva can be used as a screening method because salivary glucose levels were found to be significantly higher in diabetics.

Subjects in the age group of $36-40$ years were observed to have the highest blood glucose levels while those in the $46-50$ year age range were seen to have the highest salivary glucose levels. Since diabetes is now being diagnosed in younger age groups, it is of high importance that people at risk of developing type II diabetes are identified early and lifestyle modifications introduced to prevent the transition of prediabetes to frank diabetes.

High birth weight caused by maternal gestational diabetes mellitus (GDM) is later associated with DM. This could be because foetal over nutrition permanently 'programmes' organ structure and metabolism. After birth, obesity, smoking, unhealthy diets and sedentary behaviour interacts with foetal exposures and increase disease risk. These metabolic effects in offspring have been observed after alteration of maternal diet in early and postnatal periods in animal studies. Evidence in humans, though, is limited. ${ }^{37}$

\section{Limitation}

Small sample size was our main limitation. By studying larger populations, we can develop a better understanding of the effect of age on blood glucose and salivary glucose levels.

\section{Conclusion}

Salivary glucose levels are significantly higher in diabetics in both, fasting and postprandial states in this study which means that salivary glucose estimation can be used as a mass screening method for diabetes in large populations. However, no correlation was seen between blood and salivary glucose levels. Further studies with greater sample size which help prove a correlation would open up opportunities for salivary diagnostics in diabetics and help reduce the number of undiagnosed cases especially if these methods are non - invasive. Juvenile diabetics and patients with gestational diabetes mellitus would be most benefitted as multiple pricks will not be required for drawing blood and multiple sampling is possible. Diagnosis of DM in young adults shows a temporal shift in the age of diagnosis of DM. This calls for early diagnosis and management to prevent the dreaded complications of this disease.

\section{Acknowledgements}

We would like thank all the participants, who volunteered for this study.

\section{References}

1. American Diabetes Association (2011) Diagnosis and classification of diabetes mellitus. Diabetes Care 34: S62-9.

2. The International Expert Committee (2009) International Expert Committee Report on the Role of the A1C Assay in the Diagnosis of Diabetes. Diabetes Care 32: 1327-1334.

3. Inoue M, Inoue K, Akimoto K. Effects of age and sex in the diagnosis of type 2 diabetes using glycated haemoglobin in Japan: the Yuport Medical Checkup Centre study. PloS one. 2012 Jul 5;7(7):e40375. 
4. Heianza Y, Hara S, Arase Y, Saito K, Tsuji $\mathrm{H}$, et al. (2012) Impact of introducing HbA1c into the diagnostic criteria on prevalence and cardiovascular risk profiles of individuals with newly diagnosed diabetes in Japan: The Toranomon Hospital Health Management Center Study 2 (TOPICS 2). Diabetes Res Clin Pract 95: 283-290.

5. Lipska KJ, De Rekeneire N, Van Ness PH, Johnson KC, Kanaya A, et al. (2010) Identifying dysglycemic states in older adults: implications of the emerging use of hemoglobin A1c. J Clin Endocrinol Metab 95: 5289-5295.

6. Selvin E, Coresh J, Brancati FL (2006) The burden and treatment of diabetes in elderly individuals in the U.S. Diabetes Care 29: 2415-2419.

7. Motta M, Bennati E, Ferlito L, Malaguarnera M (2006) Diabetes mellitus in the elderly: diagnostic features. Arch Gerontol Geriatr 42: 101-106.

8. Panchbai AS, Degwekar SS, Bhowte RR. Estimation of salivary glucose, salivary amylase, salivary total protein and salivary flow rate in diabetics in India. J Oral Sci. 2010;52 (3):359-368.

9. International Diabetes Federation [homepage on the Internet]. c2017 [updated 2017; cited 2017] Available from: www.idf.org

10. Dodds MW, Johnson DA, Yeh CK. Health benefits of saliva: a review. J Dent.2005 Mar;33 (3):223-33.

11. Powers AC. Diabetes mellitus: Management and Therapies. In: Fauci A, Kasper D, Hauser S, editors. Harrison's principles of internal medicine. New York: McGraw-Hill, 2015; p. 2407-2422.

12. Powers AC. Diabetes mellitus: Complications. In: Fauci A, Kasper D, Hauser S, editors. Harrison's principles of internal medicine. New York: McGraw-Hill, 2015; p. 2422-2430
13. Chan JC, Malik V, Jia W, Kadowaki T, Yajnik CS, Yoon KH, et al. Diabetes in Asia: epidemiology, risk factors and pathophysiology. JAMA. 2009;301 (20):2129-2140.

14. Satish BN, Srikala P, Maharudrappa B, Awanti SM, Kumar P, Hugar D. Saliva: A tool in assessing glucose levels in Diabetes Mellitus. J Int Oral Health. 2014; 6(2):114117.

15. Ramachandran A, Mary S, Yamuna A, Murugesan N, Snehalatha C. High prevalence of Diabetes and cardiovascular risk factors associated with urbanization in India. Diabetes Care. 2008 May;31 (5):8938.

16. Panchbai AS, Degwekar SS, Bhowte RR. Estimation of salivary glucose, salivary amylase, salivary total protein and salivary flow rate in diabetics in India. J Oral Sci. 2010;52 (3):359-368.

17. Sariri R, Varasteh A, Erfani A. Alternations in salivary glucose during ramadan fasting. Sci Res. 2010;2 (7): 769-772.

18. Vasconcelos AC, Soares MS, Almedia PC, Soares TC. Comparative study of the concentration of salivary and blood glucose in type 2 diabetic patients. J Oral Sci. 2010;52 (2):293-8.

19. Belazi MA, Galli - Tsinopoulou A, Drakoulakos D, Fleva A, Papanayiotou PH. Salivary alterations in insulin - dependent diabetes mellitus. Int J Paediatr Dent. 1998 Mar;8 (1):29-33.

20. Gupta S, Sandhu SV, Bansal H, Sharma D. Comparison of salivary and serum glucose levels in diabetic patients. Journal of diabetes science and technology. 2014 Oct 7;9(1):91-6.

21. Harris MI, Cowie CC, Howie LJ. American Diabetes Association consensus statement on self-monitoring of blood glucose. Diabetes Care. 1987;10:95-9.

22. Mohan V, Sandeep S, Deepa R, Shah B, Varghese C. Epidemiology of type 2 
diabetes: Indian scenario. The Indian journal of medical research. 2007 Mar 1;125(3):21730 .

23. Dickinson S, Colagiuri S, Faramus E, Petocz P, Brand-Miller JC. Postprandial hyperglycemia and insulin sensitivity differ among lean young adults of different ethnicities. J Nutr. 2002;132 (9):2574-2579.

24. Hu FB. Globalization of diabetes: the role of diet, lifestyle, and genes. Diabetes Care. 2011 Jun;34 (6):1249-57.

25. Ganong WF. Endocrine functions of the pancreas and regulation of carbohydrate metabolism. In: Barrett KE, Barman SM, Boitano S, Brooks HL, editors. Review of Medical Physiology, 25th ed. New York: McGraw-Hill, 2015; p. 429-449

26. Darwazeh AM, MacFarlane TW, McCuish A, Lamey PJ. Mixed salivary glucose levels and candidal carriage in patients with diabetes mellitus. Journal of Oral Pathology \& Medicine. 1991;20:280-283.

27. Murrah VA, Crosson JT, Sauk JJ. Parotid gland basement membrane variation in diabetes mellitus. J Oral Pathol. 1985 Mar;14 (3):236-46.

28. Babu NA, Masthan KM, Bhattacharjee T, Elumalai M. Saliva-the key regulator of oral changes in diabetes patients. IJPSR. 2014;5 (7):2579-2583.

29. IvanovskiK, Naumovski V, Kostadinova M, Pesevska S, Drijanska K, Filipce V. Xerostomia and salivary levels of glucose and urea in patients with diabetes. Prilozi Macedonian Academy of Sciences and Arts, Section of Biological and Medical Sciences. 2012;33 (2):219.

30. Navalkar A, Bhoweer A. Alterations in whole saliva constituents in patients with diabetes mellitus and periodontal disease. JIAOMR. 2011;23 (4):498-501
31. Vaziri PB, Vahedi M, Mortazavi H, Abdollahzadeh S, Hajilooi M. Evaluation of salivary glucose, IgA and flow rate in diabetic patients: a case-control study. Journal of dentistry (Tehran, Iran). 2010;7 (1):13-8.

32. McAdams MA, Van Dam RM, Hu FB. Comparison of self-reported and measured BMI as correlates of disease markers in U.S. adults. Obesity. 2007;15:188.

33. Zhang W, Wang ML, inventors; Northeastern University., assignee. Saliva glucose monitoring system. United States patent 20140197042.Jul 7.

34. Mucci DA, Clark RG, Fox JS, inventors; Quick Technologies., assignee. Mobile smart device infrared light measuring apparatus, pimethod, and system for analyzing substances. United States patent 20140027641. 2014 Jan 30.

35. Ahmed AF, Fayed MS, Yasser MH, Lincz LF. Retrospective study among primary care Type 2 diabetes mellitus patients within the city of Zliten, Libya, represented high incidence of early onset of disease diagnosis. Libyan Journal of Medical Sciences. 2019 Jan 1;3(1):13.

36. TODAY Study Group. A clinical trial to maintain glycemic control in youth with type 2 diabetes. New England Journal of Medicine. 2012 Jun 14;366(24):2247-56.

37. Fall CH, Kumaran K. Metabolic programming in early life in humans. Philosophical Transactions of the Royal Society B. 2019 Feb 25;374(1770): 20180123.

38. Dhawan D, Sharma S. Metabolic syndrome: The bane of Indian population. 